\title{
Does Ejaculation Increase Female Sexual Orgasm And Satisfaction? \\ http://bjas.journals.ekb.eg
}

A.K.Habib, I.Y.Abdalah and S.E.Ibrahem

Dermatology and Andrology Dept., Faculty of Medicine, Benha Univ., Benha, Egypt

E-Mail:Monnyhabib45@gmail.com

\begin{abstract}
Although links between ejaculatory control or intravaginal ejaculatory latency time and female sexual function have been reported in the past, until recently little research or attention has focused on the effectof ejaculation on female satisfaction and orgasm.To assess the importance of ejaculation for femalesexual function and satisfaction.This was a cross-sectional study including 221 sexually active married womenaged20-59 years,A self- report questionnaire designed by the investigators was used $58.4 \%$ of women considered it very important that the partner ejaculates during intercourse. $64.3 \%$ ofwomen preferred that the partner ejaculates before they reach orgasm, whereas for $24 \%$ this did not matter. $58.4 \%$ of women stated that they experienced a more intense orgasm when their partner ejaculated during vaginal intercourse.21\% of women regarded the quantity of ejaculate Volume as an expression of their own sexual attractiveness.
\end{abstract}

Keywords: Ejaculation, Female Sexual Dysfunction, Partner Distress,Ejaculation Timing and condom, Benha.

\section{Introduction}

Male ejaculatory dysfunctions can seriously affect a man's psychological and physical wellbeing, regularly coming about in uplifted trouble,diminished fearlessness, expanded danger of mental issue, and decreased sexual action [1].

In a study by Brock et al.,men worried about ejaculatory brokenness influence adversely on their accomplices and demonstrated a diminished recurrence of sexual action contrasted and sound subjects. During sex, men with untimely discharge (PE) referenced that they were engrossed with musings in regards to their control of discharge and this prompts sexual brokenness, for example, decline in want, excitement and orgasmic brokenness and relationship disaPPointment of their female accomplices and now and again in any event, prompting resulting relationship separates [2].

Two investigations surveying fulfillment with sex, individual pain, and relational troubles in sound female accomplices of men with and without PE both found that female accomplices of men with PE detailed increasingly relational challenges, were less haPPy with sex, and more by and by upset than female accomplices of nonPE men. What's more, results showed that ladies with a PE accomplice had essentially progressively sexual issues contrasted and ladies with sound accomplices [3].

In an examination by Hobbs et al., the greater part of ladies with a PE accomplice showed orgasmic issues, while just $23.9 \%$ of the benchmark group griped of orgasmic rarity[4].

Truth be told, not many examinations have investigated the idea of the connection between male discharge and female sexuality, for example, the particular outcomes of PE that might impact female sexual fulfillment and climax capacity. In an examination directed on 1,463 females with a PE accomplice were interrogated concerning their impression of PE and which explicit viewpoints they saw as risky.As anyone might expect,a climax subordinate impact could be watched, with ladies with rare climaxes thinking about adaptability(ie, inventiveness in bed) more significant than the length of intercourse, while ladies with a high climax capacity wanted for a more drawn out term of intercourse and were progressively bothered by their accomplice's ejaculatory brokenness $[5]$.

At last in spite of proof demonstrating outcomes of ejaculatory brokenness on the two accomplices, just constrained information exists of how significant male discharge and its different qualities, for example, discharge Volume and power may be for female sexual capacity and fulfillment [5].

\section{Aim of the work}

This study aims to assess the importance of intravaginal ejaculation and its effect on female orgasm and satisfaction.

\section{Patients and methods}

After obtaining aPProval from the Department of Dermatology and Andrology and the Research Ethics Committee in Faculty of Medicine, Benha University we proceed with asking the participants to complete our questionnaire. The study was performed on 221 women attending the dermatology and andrology outpatient clinic in General Zagazig Hospital in ElSharqiagovernorate. The tool used was a self-report questionnaire, and details of the questionnaire were explained to the women before taking their informed consent. Each woman was asked to fill the questionnaire. To ensure that all gathered information was kept confidential and the subject was anonymous, each questionnaire was handed in an open envelope and after filling it, the subject sealed the envelope and put it in a basket containing other sealed envelopes. The Incorporation criteria were sexually active married women. Avoidance criteria were illiterate, less than 18 years women. The current study was conducted as a cross-sectional study. Results were collected, tabulated, statistically analyzed by computer program SPSS version 22. Two types of statistics were done descriptive: e.g. number and percent $(\%)$, analytical: Chi-Squared $\left(\chi^{2}\right)$ test was used to calculate difference between qualitative variables. and $\mathrm{p}$ value, where non-significant difference if $p>0.05$, significant difference if $p<0.05$ and highly significant difference if $\mathrm{p}<0.001$. 


\section{Results}

This study was conducted on 221 married women to assess the importance of intravaginal ejaculation and its effect on female orgasm and satisfaction.

Table (1) shows that $48.9 \%$ of the studied group belonged to age group from 30 to 39 years, only $7.7 \%$ of them were above 50 years, $55.7 \%$ of the studied group were urban residents, $64.7 \%$ of them were university educated, despite that only $28.5 \%$ were working.
Table (2) shows that the commonest coital frequency was once/week $(45.2 \%), 72.4 \%$ of them preferred vaginal intercourse, $45.7 \%$ can reach orgasm in more than $50 \%$ of sexual encounters. Inability to have orgasm was most commonly due to work tensions or problems $(29.4 \%)$. Dyspareunia was a complaint of $40.7 \%$ of participants.

Table (1) Demographic data of the studied groups.

\begin{tabular}{lcc}
\hline Item & \multicolumn{2}{c}{ Studied group $(\mathbf{n = 2 2 0})$} \\
\cline { 2 - 3 } & $\mathbf{n}$ & $\mathbf{\%}$ \\
\hline Age (years) & 6 & \\
$\mathbf{2 0}$ & 56 & 2.7 \\
$\mathbf{2 0 - 2 9}$ & 108 & 25.3 \\
$\mathbf{3 0 - 3 9}$ & 34 & 48.9 \\
$\mathbf{4 0 - 4 9}$ & 17 & 15.4 \\
$\mathbf{2 5 0}$ & & 7.7 \\
Residence & 98 & \\
Rural & 123 & 44.3 \\
Urban & & 55.7 \\
Education level & 40 & \\
Read and write & 38 & 18.1 \\
Secondary education & 143 & 17.2 \\
University education & & 64.7 \\
Occupation & 158 & \\
No & 63 & 71.5 \\
Yes & & 28.5 \\
\hline
\end{tabular}

Table (2) Sexual activity and different aspects of orgasm among the studied women $(n=221)$.

\begin{tabular}{lcc}
\hline Variable & \multicolumn{2}{c}{ Studied group $(\mathbf{n = 2 2 1})$} \\
\cline { 2 - 3 } & $\mathbf{n}$ & $\mathbf{\%}$ \\
\hline How often do you have sex & 9 & 4.1 \\
Daily & 53 & 24.0 \\
2-3 times per week & 100 & 45.2 \\
Once per week & 35 & 15.8 \\
1-2 per month & 24 & 10.9 \\
* Once per month & & \\
*Preferred sexual activity & 66 & 29.9 \\
Kissing & 97 & 43.9 \\
Caressing & 160 & 72.4 \\
Vaginal intercourse & 2 & 0.9 \\
Oral sex & & \\
Frequency of reaching orgasm: & 79 & 35.7 \\
Almost all times of sexual encounters & 31 & 14.0 \\
<50\% of times of sexual encounters & 101 & 45.7 \\
>50\% of times of sexual encounters & 10 & 4.5 \\
Rare or never & & \\
Causes of inability to reach orgasm & 41 & 18.6 \\
No sufficient time foreplay & 64 & 29.0 \\
Feeling pain & 51 & 23.1 \\
Feeling tired from work & 65 & 29.4 \\
Work tensions and problems & & \\
Pain with sexual activity & & 5.4 \\
\hline Almost all times of sexual encounters & 12 & \\
\hline
\end{tabular}




\begin{tabular}{lll}
\hline$<\mathbf{5 0 \%}$ of times of sexual encounters & 90 & 40.7 \\
$\mathbf{> 5 0 \%}$ of times of sexual encounters & 39 & 17.6 \\
Rare or never & 80 & 36.2 \\
\hline
\end{tabular}

*More than one choice is allowed

Table (3) Different aspects of ejaculation among the studied women $(n=221)$.

\begin{tabular}{|c|c|c|}
\hline \multirow[t]{2}{*}{ Variable } & \multicolumn{2}{|c|}{$\begin{array}{l}\text { Studied group } \\
\quad(\mathrm{n}=\mathbf{2 2 1})\end{array}$} \\
\hline & $\mathbf{N}$ & $\%$ \\
\hline \multicolumn{3}{|c|}{ Do you generally prefer your husband ejaculates before you reach orgasm? } \\
\hline No & 26 & 11.8 \\
\hline yes & 142 & 64.3 \\
\hline Doesn't matter & 53 & 24.0 \\
\hline \multicolumn{3}{|c|}{ How soon after penetration does your husband ejaculate? } \\
\hline Very rapid (within 1 minute) & 13 & 5.9 \\
\hline Rapid (within 5 minutes) & 90 & 40.7 \\
\hline Normally (within 10-15 minutes) & 91 & 41.2 \\
\hline Slowly (more than 15 minutes) & 27 & 12.2 \\
\hline \multicolumn{3}{|c|}{ Do you experience more intense orgasm when your husband ejaculates during vaginal intercourse? } \\
\hline Yes & 129 & 58.4 \\
\hline No & 18 & 8.1 \\
\hline Doesn't matter & 57 & 25.8 \\
\hline I don't notice that he ejaculates & 17 & 7.7 \\
\hline \multicolumn{3}{|c|}{ Are you satisfied with your sexual life if your husband ejaculates in condom? } \\
\hline Very satisfied & 27 & 12.2 \\
\hline Moderately satisfied & 35 & 15.8 \\
\hline Equally satisfied and dissatisfied & 29 & 13.1 \\
\hline Moderately dissatisfied & 66 & 29.9 \\
\hline Unsatisfied & 64 & 29.0 \\
\hline \multicolumn{3}{|c|}{ Rate of sexual desire or interest with ejaculation in condom } \\
\hline Very high & 12 & 5.4 \\
\hline High & 49 & 22.2 \\
\hline Moderate & 85 & 38.5 \\
\hline Low & 75 & 33.9 \\
\hline \multicolumn{3}{|c|}{ Do you perceive the quantity of your husbands ejaculate as an expression of your own sexual attractiveness? } \\
\hline Completely agree & 11 & 5.0 \\
\hline Agree & 35 & 15.8 \\
\hline Neither agree nor disagree & 25 & 11.3 \\
\hline Disagree & 104 & 47.1 \\
\hline Completely disagree & 46 & 20.8 \\
\hline
\end{tabular}

Table (4) The reason for man to allude for sexual intercourse according to the studied groups.

\begin{tabular}{lcc}
\hline Variable & \multicolumn{2}{c}{$\begin{array}{c}\text { Studied group } \\
(\mathbf{n = 2 2 1})\end{array}$} \\
\cline { 2 - 3 } & $\mathbf{n}$ & \% \\
\hline Does your husband use male condom during your sexual relationship? & & \\
Yes & 77 & 34.8 \\
No & 144 & 65.2 \\
& & $(\mathrm{n}=77)$ \\
the indication of condom use: & & \\
Contraception & 55 & 71.4 \\
Treatment of premature ejaculation & 9 & 11.7 \\
Prevention of STIs & 8 & 10.4 \\
Other & 5 & 6.5 \\
\hline
\end{tabular}


Table (3) shows that $2 / 3$ of the studied women $(64.3 \%)$ prefer her husband ejaculates before reaching orgasm, $41.2 \%$ of them reported that their husbands ejaculate normally (within 10-15 minutes) after penetration, $58.4 \%$ experience more intense orgasm when their husbands ejaculate during vaginal intercourse,
$29 \%$ of the studied group were unsatisfied with their sexual life if husbands ejaculate in condom.

Table (4) shows that $34.8 \%$ of husbands use male condom during sexual relationship and the condom is used as a method of contraception in $71.4 \%$ or a treatment of premature ejaculation and prevention of STIs in $11.7 \%$ and $10.4 \%$ respectively.

\section{Relations between results}

Table (5) Age distribution of the studied sample according to some orgasmic aspects.

\begin{tabular}{|c|c|c|c|c|c|c|c|c|c|c|c|}
\hline \multirow[t]{3}{*}{ Variables } & \multicolumn{11}{|c|}{ Age $(n=221)$} \\
\hline & \multicolumn{2}{|c|}{$\begin{array}{c}<20 \\
(n=6) \\
\end{array}$} & \multicolumn{2}{|c|}{$\begin{array}{c}20-29 \\
(n=56) \\
\end{array}$} & \multicolumn{2}{|c|}{$\begin{array}{c}30-39 \\
(n=108)\end{array}$} & \multicolumn{2}{|c|}{$\begin{array}{c}40-49 \\
(n=34)\end{array}$} & \multicolumn{2}{|c|}{$\begin{array}{c}\geq 50 \\
(n=17)\end{array}$} & \multirow[t]{2}{*}{ P - value } \\
\hline & $\mathbf{n}$ & $\%$ & $\mathbf{n}$ & $\%$ & $\mathbf{N}$ & $\%$ & $\mathbf{n}$ & $\%$ & $\mathbf{n}$ & $\%$ & \\
\hline \multicolumn{12}{|l|}{ Frequency of reaching orgasm: } \\
\hline Almost all times of sexual encounters & 2 & 33.3 & 17 & 30.4 & 27 & 25.0 & 23 & 67.6 & 10 & 58.8 & \multirow[t]{4}{*}{$0.000 *$} \\
\hline$<50 \%$ of times of sexual encounters & 0 & 0.0 & 9 & 16.1 & 9 & 8.3 & 8 & 23.5 & 5 & 29.4 & \\
\hline$>50 \%$ of times of sexual encounters & 4 & 66.7 & 27 & 48.2 & 67 & 62.0 & 3 & 8.8 & 0 & 0.0 & \\
\hline Rare or never & 0 & 0.0 & 3 & 5.4 & 5 & 4.6 & 0 & 0.0 & 2 & 11.8 & \\
\hline \multicolumn{12}{|l|}{ Causes of inability to reach orgasm } \\
\hline No sufficient time foreplay & 4 & 66.7 & 11 & 19.6 & 23 & 21.3 & 0 & 0.0 & 3 & 17.6 & \multirow[t]{4}{*}{$0.000^{*}$} \\
\hline Feeling pain & 2 & 33.3 & 23 & 41.1 & 21 & 19.4 & 12 & 35.3 & 6 & 35.3 & \\
\hline Feeling tired from work & 0 & 0.0 & 12 & 21.4 & 37 & 34.3 & 2 & 5.9 & 0 & 0.0 & \\
\hline Work tensions and problems & 0 & 0.0 & 10 & 17.9 & 27 & 25.0 & 20 & 58.8 & 8 & 47.1 & \\
\hline \multicolumn{12}{|l|}{ Pain with sexual activity } \\
\hline Almost all times of sexual encounters & 0 & 0.0 & 0 & 0.0 & 10 & 9.3 & 2 & 5.9 & 0 & 0.0 & \multirow[t]{4}{*}{$0.000 *$} \\
\hline$<50 \%$ of times of sexual encounters & 2 & 33.3 & 32 & 57.1 & 49 & 45.4 & 2 & 5.9 & 5 & 29.4 & \\
\hline$>50 \%$ of times of sexual encounters & 0 & 0.0 & 7 & 12.5 & 20 & 18.5 & 12 & 35.3 & 0 & 0.0 & \\
\hline Rare or never & 4 & 66.7 & 17 & 30.4 & 29 & 26.9 & 18 & 52.9 & 12 & 70.6 & \\
\hline
\end{tabular}

Chi-square test

$*$ p-value $<0.05$ statistical significance.

Table (5) shows that there was a statistically significant difference in frequency of inability to reach orgasm which increases with aging. Short time for foreplay decreases in frequency with age. Dyspareunia frequency was noticed to decrease with advance in age.

Table (6) Age distribution of the studied sample according to sexual activity.

\begin{tabular}{|c|c|c|c|c|c|c|c|c|c|c|c|}
\hline \multirow[t]{3}{*}{ Variables } & \multicolumn{11}{|c|}{ Age $(n=221)$} \\
\hline & \multicolumn{2}{|c|}{$\begin{array}{c}<20 \\
(n=6)\end{array}$} & \multicolumn{2}{|c|}{$\begin{array}{c}20-29 \\
(n=56)\end{array}$} & \multicolumn{2}{|c|}{$\begin{array}{c}30-39 \\
(n=108)\end{array}$} & \multicolumn{2}{|c|}{$\begin{array}{c}40-49 \\
(n=34)\end{array}$} & \multicolumn{2}{|c|}{$\begin{array}{c}\geq \mathbf{5 0} \\
(\mathbf{n}=\mathbf{1 7})\end{array}$} & \multirow[t]{2}{*}{ p - value } \\
\hline & $\mathbf{n}$ & $\%$ & $\mathbf{n}$ & $\%$ & n & $\%$ & $\mathbf{n}$ & $\%$ & $\mathbf{n}$ & $\%$ & \\
\hline \multicolumn{12}{|l|}{ How often do you have sex } \\
\hline Daily & 4 & 66.7 & 5 & 8.9 & 0 & 0.0 & 0 & 0.0 & 0 & 0.0 & $0.000^{*}$ \\
\hline 2-3 times per week & 2 & 33.3 & 10 & 17.9 & 39 & 36.1 & 0 & 0.0 & 2 & 11.8 & \\
\hline Once per week & 0 & 0.0 & 36 & 64.3 & 53 & 49.1 & 4 & 11.8 & 7 & 41.2 & \\
\hline 1-2 per month & 0 & 0.0 & 3 & 5.4 & 12 & 11.1 & 20 & 58.8 & 0 & 0.0 & \\
\hline$<$ Once per month & 0 & 0.0 & 2 & 3.6 & 4 & 3.7 & 10 & 29.4 & 8 & 47.1 & \\
\hline \multicolumn{12}{|l|}{$\$$ Preferred sexual activity } \\
\hline Kissing & 2 & 33.3 & 17 & 30.4 & 47 & 43.5 & 0 & 0.0 & 0 & 0.0 & $0.000 *$ \\
\hline Caressing & 6 & 100.0 & 23 & 41.1 & 60 & 55.6 & 3 & 8.8 & 5 & 29.4 & $0.000^{*}$ \\
\hline Vaginal intercourse & 6 & 100.0 & 44 & 78.6 & 65 & 60.2 & 31 & 91.2 & 14 & 82.4 & $0.001 *$ \\
\hline Oral sex & 0 & 0.0 & 2 & 3.6 & 0 & 0.0 & 0 & 0.0 & 0 & 0.0 & 0.219 \\
\hline
\end{tabular}

$\$$ More than one choice is allowed

$*$ p-value $<0.05$ statistical significance 
Table (6) shows that having sex was more frequent with younger age groups than older age, kissing and caressing were preferred in younger age groups, while vaginal intercourse was the preferred sexual activity in almost all age groups, with highly significant difference.

Table (7) Orgasm in relation to ejaculation in condom.

\begin{tabular}{|c|c|c|c|c|c|c|}
\hline \multirow[t]{3}{*}{ Variable } & \multicolumn{4}{|c|}{ Ejaculation in condom } & \multirow[t]{3}{*}{$\chi^{2}$} & \multirow[t]{3}{*}{ p-value } \\
\hline & \multicolumn{2}{|c|}{$\begin{array}{c}\text { Yes } \\
(n=77)\end{array}$} & \multicolumn{2}{|c|}{$\begin{array}{c}\text { No } \\
(n=144)\end{array}$} & & \\
\hline & $\mathbf{n}$ & $\%$ & $\mathbf{n}$ & $\%$ & & \\
\hline \multicolumn{7}{|l|}{ Frequency of reaching orgasm: } \\
\hline Almost all times of sexual encounters & 20 & 26.0 & 59 & 41.0 & 10.41 & $0.015^{*}$ \\
\hline$<50 \%$ of times of sexual encounters & 7 & 9.1 & 24 & 16.7 & & \\
\hline$>50 \%$ of times of sexual encounters & 45 & 58.4 & 56 & 38.9 & & \\
\hline Rare or never & 5 & 6.5 & 5 & 3.5 & & \\
\hline \multicolumn{7}{|l|}{ Causes of inability to reach orgasm } \\
\hline No sufficient time foreplay & 22 & 28.6 & 19 & 13.2 & 18.17 & $0.000 *$ \\
\hline Feeling pain & 19 & 24.7 & 45 & 31.3 & & \\
\hline Feeling tired from work & 24 & 31.2 & 27 & 18.8 & & \\
\hline Work tensions and problems & 12 & 15.6 & 53 & 36.8 & & \\
\hline \multicolumn{7}{|l|}{ Pain with sexual activity } \\
\hline Almost all times of sexual encounters & 6 & 7.8 & 6 & 4.2 & 3.50 & 0.321 \\
\hline$<50 \%$ of times of sexual encounters & 27 & 35.1 & 63 & 43.8 & & \\
\hline$>50 \%$ of times of sexual encounters & 17 & 22.1 & 22 & 15.3 & & \\
\hline Rare or never & 27 & 35.1 & 53 & 36.8 & & \\
\hline
\end{tabular}

\footnotetext{
Chi-square test

$*$ p-value $<0.05$ statistical significance.
}

Table (7) shows that frequency of reaching orgasm was lower in women with husbands who use condom; where $26 \%$ of women with husbands who use condom reach orgasm almost all times of sexual encounters compared to $41 \%$ of women whose husbands didn't use condom with a statistically significant difference. There was no significant difference between ejaculation in condom and pain during sexual activity.

Table (8) Sexual activity in relation to ejaculation in condom.

\begin{tabular}{|c|c|c|c|c|c|c|}
\hline \multirow[t]{3}{*}{ Variable } & \multicolumn{4}{|c|}{ Ejaculation in condom } & \multirow[t]{3}{*}{$\chi^{2}$} & \multirow[t]{3}{*}{ p-value } \\
\hline & \multicolumn{2}{|c|}{$\begin{array}{c}\text { Yes } \\
(n=77)\end{array}$} & \multicolumn{2}{|c|}{$\begin{array}{c}\text { No } \\
(n=144)\end{array}$} & & \\
\hline & $\mathbf{n}$ & $\%$ & $\mathbf{n}$ & $\%$ & & \\
\hline \multicolumn{7}{|c|}{ How often do you have sex } \\
\hline Daily & 2 & 2.6 & 7 & 4.9 & 21.75 & $0.000 *$ \\
\hline 2-3 times per week & 30 & 39.0 & 23 & 16.0 & & \\
\hline Once per week & 36 & 46.8 & 64 & 44.4 & & \\
\hline 1-2 per month & 5 & 6.5 & 30 & 20.8 & & \\
\hline$<$ Once per month & 4 & 5.2 & 20 & 13.9 & & \\
\hline \multicolumn{7}{|c|}{ Preferred sexual activity } \\
\hline Kissing & 22 & 28.6 & 44 & 30.6 & 0.094 & 0.878 \\
\hline Caressing & 29 & 37.7 & 68 & 47.2 & 1.86 & 0.201 \\
\hline Vaginal intercourse & 61 & 79.2 & 99 & 68.8 & 2.75 & 0.155 \\
\hline
\end{tabular}

Chi-square test $* \mathrm{p}$-value $<0.05$ statistical significance

Table (8) shows that there was a statistically significant difference between women whom their husbands use condom and frequency of having sex; where having sex 2-3 times per week or once per week was more common with husbands who use condom; where $39 \%$ of women whom their husbands ejaculate in the condom have sex 2-3 times per week compared to $16 \%$ of women whom their husbands didn't use condom. There was no significant difference between ejaculation in condom and preferred sexual activity.

Table (9) Ejaculation timing in relation to ejaculation in condom. 


\begin{tabular}{|c|c|c|c|c|c|c|}
\hline \multirow[t]{3}{*}{ Variable } & \multicolumn{4}{|c|}{ Ejaculation in condom } & \multirow[t]{3}{*}{$\chi^{2}$} & \multirow[t]{3}{*}{ p-value } \\
\hline & \multicolumn{2}{|c|}{ Yes } & \multicolumn{2}{|c|}{ No } & & \\
\hline & $\mathbf{n}$ & $\%$ & n & $\%$ & & \\
\hline \multicolumn{7}{|c|}{ Do you generally prefer your husband ejaculates before you reach orgasm? } \\
\hline No & 4 & 5.2 & 22 & 15.3 & 6.59 & $0.037 *$ \\
\hline yes & 57 & 74.0 & 85 & 59.0 & & \\
\hline Doesn't matter & 16 & 20.8 & 37 & 25.7 & & \\
\hline \multicolumn{7}{|c|}{ How soon after penetration does your husband ejaculate? } \\
\hline Very rapid (within 1 minute) & 2 & 2.6 & 11 & 7.6 & 14.00 & $0.003^{*}$ \\
\hline Rapid (within 5 minutes) & 21 & 27.3 & 69 & 47.9 & & \\
\hline Normally (within 10-15 minutes) & 43 & 55.8 & 48 & 33.3 & & \\
\hline Slowly (more than 15 minutes) & 11 & 14.3 & 16 & 11.1 & & \\
\hline
\end{tabular}

$*$ p-value $<0.05$ statistical significance.

Table (9) shows that there was a statistically significant difference between use of condom and ejaculation timing after penetration; where normally (within10-15minutes) was more common with women whom their husbands use condom $(55.8 \%)$ compared to $33.3 \%$ of women whom their husbands didn't use condom.

\section{Discussion}

The objective of the present study was to assess the effect of ejaculation on female orgasm and satisfaction. The study was conducted on 221 healthy sexually active women.

Among the members $58.4 \%$ experience increasingly serious climax when their spouses discharge during vaginal intercourse. In an investigation by Burri et al.,50.43\% of ladies thought of it as significant that the accomplice discharges during intercourse and $22.6 \%$ of ladies expressed that they encountered a progressively exceptional climax when their accomplice discharged during vaginal intercourse [6]. This is fairly in concurrence with past outcomes by Burri et al., who discovered noteworthy contrasts in climax capacity of ladies according to the significance they doled out to ejaculatory control. In addition, in their investigation, ladies announcing a high climax recurrence additionally favored a more extended intercourse length and were increasingly troubled by the absence of ejaculatory control contrasted and ladies with a lower orgasmic capacity [5].

Many women find it very distressing when their male partner suffer from delayed ejaculation or the inability to ejaculate mostly because it gives them the feeling of not being desired or attractive. Also, the perception of a large ejaculation can make the women feel sexy and wanted and in contrast, a perceived smaller ejaculation Volume might negatively affect her selfesteem [6].These finding suggest the reasons making ejaculation an important aspect for women's satisfaction and sexual functioning.

In the current study, most of participants belonged to the 30-39 years age group (48.9\%) followed by the 20-29 years age group $(25.3 \%)$ which means that most of the participants were in the age of sexual activity. The current result showed that $64.7 \%$ of the participants were well educated to ensure the accuracy of the results and illiterate women were excluded to let participants fill the questionnaire themselves to ensure privacy.

As regard coital frequency, the commonest frequency was once per week $(45.2 \%)$ followed by $2-3$ times per week $(24 \%)$ and less than once per month frequency was reported by $15.8 \%$ of the participants. These results are in disagreement with a study by Younis et al.,[7].The commonest coital frequency was 2-3 per week $(64 \%)$ followed by once per month $(18 \%)$ in their study on a group of Egyptian women. A less than once per month frequency was reported by $7.8 \%$ of their participants. This difference may refer to increase in life problems and work tensions.

A decline in coital frequency was observed with advance in age. The frequency of once per week declined from $64.3 \%$ in the group aged $20-29$ years to $11.8 \%$ in women aged 40 years or more with a high statistically significant difference. This decline was also noticed in a study by Lindau et al.,[8].In their study women attributed this decline to partner's physical health problems, a lack of interest in sex and beliefs about aging and sexual energy. Another study by Lauman et al.[9],reported that participants said that having sex decreases by age.

Concerning orgasm only $35.7 \%$ of the participants could reach orgasm almost in each intercourse and only $4.5 \%$ of the participants never or rarely had experienced orgasm. This is in agreement with Laumannet al.,andIbrahim et al.,[10-11].

It was found that the commonest cause of failure to reach orgasm was life problems and work tensions $(29.4 \%)$, feeling pain (29\%), feeling tired from work (23\%) and no sufficient time for foreplay (18.6\%). Pain and loss of interest were the main causes of failure to reach orgasm as mentioned by Abd El-Rahman et al., [12].Younis et al., found that the commonest cause of failure to reach orgasm was being not interested $(28.2 \%)$, feeling tired (23.9\%), lack of time for foreplay (20.7\%), pain during coitus $(13.6 \%)$ and premature ejaculation of the husband (13.6\%) [7].

In our study, the frequency of reaching orgasm was lower in women with husbands who use condom; where $26 \%$ of women with husbands who use condom reach 
orgasm almost all times of sexual encounters compared to $41 \%$ of women whose husbands didn't use condom with a statistically significant difference. This is in agreement with a study by Younis et al.,who found that condom has a negative effect on orgasm frequency in $28 \%$ of respondents. Seventy-two percent of their participants thought that their sexual life would be better without condom use; the reason that made women reject male condoms was to have better sexual contact sensation and to be physically comfortable [13].

Thirty percent of participants were moderately dissatisfied with their sexual life if husbands ejaculate in condom. The same conclusion was reported by Bjekić et al., . The results of their study indicated that both women and men believed that the use of condom during vaginal intercourse significantly reduced sexual pleasure and the second most frequent reason for not using a condom in their participants was the feeling that condom decreased sexual pleasure [14]. In a study by Randolph et al.,both women and men rated unprotected vaginal intercourse as more pleasurable than protected vaginal sex [15].

Pleasure plays a central role in motivating human sexual activity Consequently, any artifice that interferes with the pleasures of sex is likely to be avoided or accepted reluctantly [16-17].

Condoms interpose a mechanical barrier between sex partners, limit physical contact, reduce tactile sensation, and attenuate heat transduction, all of which reduce sexual pleasure. This reduction in pleasure is one of the main reasons people cite for decreasing condom use [18-19-20-21] this may explain the finding in our study when we asked about the rate of sexual desire or interest with ejaculation in condom where two-thirds of respondents weren't interested when their husbands intend to use condom.

In the current work $40.7 \%$ of the members had encountered torment during copulation in under half of sexual experiences and dyspareunia recurrence was seen to diminish with advance in age with measurably huge contrast. Mitchell et al., announced that difficult sex is most noteworthy in youthful women(16-24 years) and those in later midlife (55-65 years) detailing excruciating sex was emphatically connected with encountering other sexual capacity issues, vaginal dryness, nervousness and absence of haPPiness regarding sex. The experience of torment was additionally connected with different parts of sexual capacity (counting pain and disaPPointment with sexual coexistence) and sexual relationship factors [22].

In the present work $34.8 \%$ of husbands use male condom during sexual relationship. This is in agreement with a study by Kabbash et al., who conducted a study on a randomly selected sample of 2304 males aged 15-49 from four governorates in lower Egypt to assess their knowledge and attitudes towards condom use. Only $23.9 \%$ had ever used condom, mainly for contraception but $26.8 \%$ would consider using them in the future. Among the 552 participants who reported using condoms, the main reasons for condom use were for contraception $(56.2 \%)$ and for prevention of STIs
(35.0\%); $5.6 \%$ used them for both contraception and prevention of STIs. Only 3.3\% reported using condom during menses [23].

In our study the condom is used as a method of contraception in $71.4 \%$ or a treatment of premature ejaculation and prevention of STIs in $11.7 \%$ and $10.4 \%$ respectively. The same conclusion is reported by Younis et al.,study on a sample of Egyptian participants (200) whom their husbands use condom. Contraception was the most reported cause of use by most participants (76\%). In their study when condoms were used for other purposes other than contraception such as oral sex (10\%) or increasing sexual excitation (1.5\%), pleasing spouse or even pleasing both marital sides was the main goal [13].

The low level of condom use in this study should be considered in relation to the observation that the participants life would be better without using condom and they weren't satisfied with their sexual life if their husbands ejaculate in condom.

The current study shows that there was a statistically significant difference between use of condom and ejaculation timing after penetration; where $55.8 \%$ of the participants reported that the ejaculation occurs normally (within10-15minutes) when their husbands use condom compared to $33.3 \%$ of women whom their husbands didn't use condom. The same result was reported by Younis et al., where seventy-seven percent of women found that their husbands' use of condom increases coital duration. Moderate satisfaction of coitus duration with condom use was felt by $34 \%$ of these participants. Four percent of respondents used condom for treatment of premature ejaculation[13].Philpott et al.,obtained similar results in India where condom promoters experienced longer lasting, and thus more pleasurable, intercourse [24].

In the present examination when we got some information about pace of impression of the amount of discharge as a declaration of sexual allure. Among members $47.1 \%$ didn't see the amount of spouses discharge as their very own outflow sexual allure and $21 \%$ totally oPPose this idea. In a comparable report by (Burri et al., 2018) just a minority of ladies considered ejaculatory qualities, for example, discharge Volume as their very own impression aPPeal. Nonetheless, for the individuals who did, discharge was viewed as increasingly significant for ladies who accepted that the discharge Volume mirrored their sexual engaging quality. This connection between discharge Volume and a ladies' felt engaging quality may ground on transformative senses yet additionally on subjective full of feeling reasons [6].

In our study we found that having sex was more frequent with younger age groups than older age, kissing and caressing were preferred in younger age groups, while vaginal intercourse was the preferred sexual activity in almost all age groups, with highly significant difference. This is in disagreement with a study by Sklacka and Gerymsaki,;in their examination they took a gander at whether different types of sexual movement 
(genital and non-genital)were associated with fulfillment. They found that the recurrence of cozy contact was emphatically associated with both sexual and worldwide fulfillment, however types of sexual contact impactsly affected late-life fulfillment. Over half of members favored exercises that did exclude infiltration (for example kissing $(55 \%)$ or nestling (54\%)). This might be a direct result of changes as contact that rise during the maturing procedure[25].

As Watson et al., found, for some middle-age to more seasoned people, sex was not as pleasurable as they had trusted, so they pick different types of closeness, for example, kissing and embracing[26].Gott and Hinchliff found, more established grown-ups who experience obstructions to being explicitly dynamic because of medical issues reprioritize the estimation of sex. In any case, keeping up physical closeness through non-genital contact seems vital to their well-being when penetrative sex is not, at this point conceivable [27].

More established grown-ups who favored 'contacting cozy body parts and entrance' had higher sexual fulfillment than those leaning toward progressively unobtrusive types of sexual contact, however there were no huge contrasts with respect to their worldwide life fulfillment between the individuals who occupied with 'kissing and nestling' and the individuals who occupied with genital sexual contact. These outcomes are promising, indicating that any type of cozy contact may improve life fulfillment in more established grown-ups, and the more continuous the personal contact, the more joyful the individual [25].

\section{Conclusion}

There is a significant positive relation between the partner ejaculation and female orgasm and satisfaction. Most participants experienced more intense orgasm when their partners ejaculated during intercourse.

\section{References}

[1] D.L.Patrick, S.E. Althof, J.L. Pryor, R. Rosen, D.L. Rowland, K.F. Ho, P. McNulty, M .Rothman, C .Jamieson:Premature ejaculation. An observational study of men and their partners. J Sex Med ; Vol 2, PP. 358-367,2005.

[2] G.B. Brock, F. Bénard, R.Casey, S.L. Elliott, J.B. Gajewski, J.C. Lee: Canadian male sexualhealth council survey to assess prevalence and treatment ofpremature ejaculation in Canada. J Sex Med;Vol 6, PP. 2115-2123, 2009.

[3] D.L. Rowland, D.L. Patrick, M. Rothman, D.D. Gagnon: The psychological burden of premature ejaculation. J Urol; Vol 177, PP. 1065-70,2007.

[4] K.Hobbs,T. Symonds, T.Abraham, K.May, M.F. Morri : Sexual dysfunction in partners of men with premature ejaculation. Int J Impot Res; Vol 20, PP. 512-517,2008.

[5] A.Burri, F.Giuliano, C.McMahon and H. Porst: Female partner's perception of premature ejaculation and its impact on relationship breakups, relationship quality, and sexual satisfaction. J Sex Med; Vol 11, PP. 2243-2255,2014.

[6] A.Burri, J.Buchmeier and H.Porst : The importance of male ejaculation for female sexual satisfaction and function. J Sex Med; PP. 1-9,2018.

[7] I.Younis,A. Daifulla,R. Salem,S. Abdel raouf: Coital frequency in a sample of Egyptian women. Hum androl; Vol7(2),PP. 73-83,2017.

[8] S.T.Lindau,L.pSchumm,E.O. Laumann,W. Levinson,C.O. O'Muircheartaigh,U.Waite: A study of sexuality and health among older adults in the United States. N Engl J Med; Vol 357, PP.762$774,2007$.

[9] E.O.Lauman ,A. Nicolas,D.B. Glasser, A.Paik,C. Gingell,E. Moreira andT. Wang: Sexual problems among women and men aged 40-80 y: prevalence and correlates identified in the Global Study of Sexual Attitudes and Behaviors. Int J Impot Res; Vol 17,PP.39-57,2005.

[10]E.Laumann,J. Gagnon ,R. Michael and S. Michael: The social organization of sexuality: Sexual practices in the United States. Chicago: University of Chicago Press, 1994.

[11]Z.Ibrahim,M. Ahmed and W. Sayed: Prevalence and risk factors for female sexual dysfunction among Egyptian women. Arch GynecolObstet; Vol 287(6),PP. 1173-80,2013.

[12] S.Abd El-Rahman,I.YounisandM.El-Awady: Female sexuality: in three Egyptian cities. Hum Androl; Vol 4, PP.5-10,2014.

[13]I.Younis,M. Ibrahim,D. El habbak :Taking a shower with a raincoat on women's views on male condom use. Hum Androl ;Vol 9, PP.6-13,2019.

[14] M.Bjekić,S. Sipetić-Grujičić,H. Vlajinac,A. Nikolic: Reasons for not using condoms among heterosexual men in Belgrade, Serbia. ActaDermatovenerol Croat; Vol 26, PP.58-60,2018.

[15] M.Randolph,S. Pinkerton,L.M. Bogart,H. Cecil,P.R. Abramson: Sexual pleasure and condom. Arch Sex Behave;Vol 36, PP.844-848,2017.

[16]P.R.AbramsonandS.D. Pinkerton: With pleasure: Thoughts on the nature of human sexuality. New York: Oxford University Press, 2002.

[17] S.D.Pinkerton,H. Cecil,L.M. Bogart,P.R. Abramson:The pleasures of sex: An empirical investigation. CognEmot; Vol 17, PP.341-353,2003.

[18] K.H.Choi,R. Rickman and J.A. Catania: What heterosexual adults believe about condoms. N Engl J Med; Vol331, PP.406-407,1994.

[19]R.A.Crosby,W.L. Yarber and B. Meyerson: Frequency and predictors of condom use and reasons for not using condoms among low-income women. J Sex EducTher;Vol 24, PP.63-70,1999.

[20]D.Albarracín,R.M. Ho,P.S. McNatt,W.R. Williams,F. Rhodes andC.K. Malotte :Structure of outcome beliefs in condom use. Health Psychol; Vol 19, PP.458-468,2000.

[21]T.R.Norton,L.M. Bogart,H. Cecil andS.D. Pinkerton: Primacy of affect over cognition in 
determining adult men's condom use behavior: A review. J APPIPsychol; Vol 35, PP.24932534,2005.

[22] K.R.Mitchell ,R. Geary, C.A. Graham,J. Datta,K. Wellings,P. Sonnenberg, N. Field,D. Nunns,J. Bancroft,K.G. Jones, A.M. Johnson,C. Mercer: Painful Sex (Dyspareunia) in Women: Prevalence and Associated Factors in a British Population Probability Survey. Int JGynecolObstet; Vol (11 ), PP.1689-1697,2017.

[23] I.A.Kabbash,N.M. El-Sayed,A.N. Al-Nawawy,I.K. Shady andM.S. AbouZeid: Condom use among males (15-49 Years) in lower Egypt: knowledge, attitudes and patterns of use. East Med Health J;Vol 13(6), PP.1405-16,2007.
[24] A.Philpott,W. Knerr and D. Maher: Promoting protection and pleasure: amplifying the effectiveness of barriers against sexually transmitted infections and pregnancy. Lancet; Vol 368, PP.20282031,2006.

[25] K.Sklacka and R. Gerymsaki,: Sexual activity and life satisfaction in older adults. J Jap Psycho GeriatrSoc;PP. 195-201,2018.

[26] W.K.Watson,C. StelleandN. Bell: Older women in new romantic relationships: understanding the meaning and importance of sex in later life. Int $\mathbf{J}$ Aging Hum Dev; Vol 85, PP. 33- 43,2017.

[27] M.Gott and S. Hinchliff,:How important is sex in later life? The views of older people. SocSciMed ;Vol 56, PP. 1617-1628,2003. 